\title{
Ortodontia e disfunções temporomandibulares: o estado da arte
}

\section{Paulo César R. Conti*}

É cada vez mais comum recebermos indivíduos indicados por colegas da área médica, das mais diversas especialidades, para tratamento de processos de dor e/ou disfunção da articulação temporomandibular (ATM) e da musculatura mastigatória, as conhecidas disfunções temporomandibulares (DTM). São, em geral, adolescentes ou adultos jovens que apresentam algum tipo de má oclusão esquelética e/ou dentária, já avaliados para a possível presença de outras doenças com potencial para causar dor ou disfunção no segmento cefálico, como cefaleias primárias, otites ou rinossinusites, entre tantas outras.

Ao examinar o paciente, encontra-se uma má oclusão passivel de correção ortodôntica. Inicia-se, nesse momento, uma tempestade de pensamentos, dúvidas e receios do profissional: "Devo indicar o tratamento da má oclusão para o alívio dos sinais e sintomas de DTM? Há algum tipo de aparelho que deva ser evitado nesses casos específicos? Qual o risco de piora dos sintomas com a terapia ortodôntica?".

A literatura referente à possivel relação entre o tratamento ortodôntico, a má oclusão e a DTM é saturada de trabalhos com os mais distintos modelos de execução, com conclusões também muitas vezes confusas e não-representativas da metodologia empregada. Um dos exemplos mais comuns refere-se a trabalhos de avaliação transversal, onde o indivíduo é examinado uma única vez e, eventualmente, encontra-se a coexistência de má oclusão e DTM ou de história de tratamento ortodôntico e DTM. Muitos concluem haver uma relação de causa e efeito entre essas variáveis, o que não deveria ser afirmado com base nesse tipo de pesquisa observacional. Se existente (o que também não se configura na maioria dos trabalhos desse tipo ${ }^{1,2}$ ), tal relacionamento seria somente uma associação, impossibilitando qualquer tipo de afirmação de qual fator antecedeu (ou causou) o outro.

Vários outros problemas também povoam esse cenário e alimentam a discussão acadêmica. Muitos ortodontistas afirmam haver uma melhora acentuada dos sintomas imediatamente após a instalação do aparelho ortodôntico, o que já seria efeito do "tratamento ortodôntico". Tem sido aceito, no entanto, que grande parte dessa melhora seja devida ao ato de se instalar e criar um fato "novo" dentro da cavidade bucal. Ou seja, a instalação do aparelho (e as trocas de fios...) desencadeia um processo de cognição, onde a nova situação funciona como um "alerta" para o paciente abandonar os hábitos de apertar os dentes e mascar chiclete, além de aumentar sua aderência ao tratamento, incrementando o índice de sucesso do mesmo. Esse mecanismo é muito semelhante àquele causado inicialmente pela instalação de uma placa oclusal.

Como visto até aqui, as dificuldades são enormes em relação à metodologia e interpretação de resultados. Esse processo deve-se, principalmente, à grande diversidade de variáveis presentes nessa relação: o paciente ortodôntico pode apresentar diversos tipos de má oclusão inicial, os métodos empregados para detectar ou não a presença de DTM são muitos, além da possível existência de outros fatores etiológicos, já que se trata de uma entidade multifatorial.

$\mathrm{O}$ avanço do conceito de Odontologia Baseada em Evidências (OBE), no entanto, trouxe informações importantes acerca dessa controvérsia. Revisões sistemáticas, publicações com o mais alto grau de validade científica, têm demonstrado que

* Doutor em Reabilitação Oral pela Universidade de São Paulo. Pós-doutorado pela University of Medicine and Dentistry of New Jersey, EUA. Professor associado da Universidade de São Paulo. Coordenador do Programa de Pós-graduação em Reabilitação Oral e vice-presidente da Comissão de Pósgraduação da Universidade de São Paulo. 
não há associações significativas entre a Ortodontia e as DTM ${ }^{3,5}$.

Isso significa que indivíduos submetidos a tratamento ortodôntico não apresentam maior ou menor risco de desenvolver sinais e sintomas de dor e/ou disfunção da ATM ou da musculatura mastigatória.

Esses achados são corroborados por um artigo recente $^{4}$ que relata um acompanhamento longitudinal de 20 anos em que se procurou observar se havia algum ganho com a realização do tratamento ortodôntico. Inicialmente, no ano de 1981, foram examinadas 1.081 crianças entre 11 e 12 anos de idade, e as mesmas foram novamente avaliadas após 3, 8 e 20 anos, sendo que, na última avaliação, a quantidade de indivíduos analisados foi de 337, fato normal e aceitável num estudo observacional de longa duração. Para a mensuração da presença e severidade da DTM, utilizou-se o questionário anamnésico de Helkimo, associado a um exame físico. Quando indicado, o tratamento ortodôntico foi realizado por diversos profissionais ou na Faculdade de Odontologia de Cardiff, na Grã-Bretanha. Aspectos psicológicos e comportamentais também foram mensurados por meio de inventários específicos.

A prevalência, como esperado, aumentou de 3\% na avaliação inicial para $17 \%$ após 8 anos e diminui para $10 \%$ quando os indivíduos já eram adultos, na avaliação após 20 anos. Um achado importante foi que a realização do tratamento ortodôntico não alterou de nenhuma forma os valores de prevalência, nem de incidência (casos novos), em nenhum dos períodos de avaliação. Ainda, os únicos fatores que foram considerados como preditivos para a presença de DTM na idade adulta foram o gênero feminino e a presença de sinais e sintomas de DTM na adolescência. O fato da maior probabilidade de DTM em mulheres é devido, segundo os autores, a alterações hormonais, a uma maior sensibilidade a estímulos e à expressão de lassidão ligamentar. $\mathrm{O}$ trabalho de pesquisa aqui discutido ${ }^{4}$ usou, para a definição de DTM, um questionário que não permite subclassificação das mais diversas formas da patologia (articular, com ou sem deslocamentos do disco, muscular, etc.). Isso pode ser considerado uma limitação, pois alguns fatores estudados poderiam influenciar de maneira isolada alguma estrutura do aparato mastigatório. Esse fato, no entanto, não interfere com a qualidade da pesquisa ou com a interpretação dos dados, realizada de maneira correta por análise estatística adequada.

O fato da presença da DTM na adolescência predizer a doença na vida adulta nos alerta para a necessidade de controle de sintomas de maneira adequada para essa população, como forma de diminuição de risco futuro. A manutenção de sintomas por longos períodos leva, frequentemente, a alterações neuronais que podem se tornar irreversíveis. Deve ficar claro, porém, que esse controle de sintomas deve ser feito de maneira não-invasiva e reversível.

Após analisarmos os fatos acima, fica claro que não se deve sugerir terapia ortodôntica com o intuito de "prevenir" ou tratar sinais e sintomas de DTM. Por outro lado, também fica entendido que a Ortodontia consciente e bem realizada não deve ser vista como a "vilã" para pacientes que venham a apresentar DTM.

\section{REFERÊNCIAS}

1. CONTI, A. C. C. F.; FREITAS, M. R.; CONTI, P. C. R. Avaliação da posição condilar e disfunção temporomandibular em pacientes com má oclusão de Classe II submetidos à protrusão mandibular ortopédica. R. Dental Press Ortodon. Ortop. Facial, Maringá, v. 13, n. 2, p. 49-60, mar./abr. 2008.

2. CONTI, A. et al. Relationship between signs and symptoms of temporomandibular disorders and orthodontic treatment: A cross-sectional study. Angle Orthod., Appleton, v. 73, no. 4, p. 411-417, Aug. 2003.

3. KIM, M. R.; GRABER, T. M.; VIANA, M. A. Orthodontics and temporomandibular disorder: A meta-analysis. Am. J. Orthod. Dentofacial Orthop., St. Louis, v. 121, no. 5, p. 438-446, 2002.

4. MAcFARLANE, T. V. et al. Twenty-year cohort study of health gain from orthodontic treatment: Temporomandibular disorders. Am. J. Orthod. Dentofacial Orthop., St. Louis, v. 135 , no. 6, p. 692.e1-692.e8, 2009.

5. MOHLIN, B. et al. TMD in relation to malocclusion and orthodontic treatment: A systematic review. Angle Orthod., Appleton, v. 77, no. 3, p. 542-548, 2007.

Endereço para correspondência

Paulo César R. Conti

Al. Octávio Pinheiro Brisola, 9-75

CEP: 17.012-901 - Bauru / SP

E-mail: pcconti@fob.usp.br 